مجلة كلية التربية الرياضية - جامعة بغداد * المجلد الثامن والعشرون ** العدد الأول ** لسنة

\title{
تأثير منهج تدريبي مقترح في إنقاص الوزن وبعض المتغيرات الوظيفية في إنية
}

أ.د. حمدان رحيم الكبيسي م.د. ابتهاج رفعت حسين

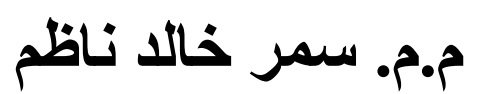

1430

مستخلص البحث باللغة العربية.

هدفت الدراسة الى التعرف على تأثير المنهج التدريبي على بعض المتغيرات الوظيفية وعلى وزن الجسم للأساتذة في دورة تخفيض الوزن والتعرف على نسبة التطور الحاصل على بعض المتغيرات الوظيفية على وزن الجسم للأساتذة الششاركين في دورة تخفيض الوزن.

أجريت الدراسة على عينة من أساتذة كلية التربية / الجامعة المستتصرية وعددهم (25) أستاذ من مجموع (34) أستاذ من المشتركين في دورة تخفيض الوزن الزائد واستخدمت الطريقة العشوائية في اختبار العينة.

واظهرت النتائج في الاختبارات الوظيفية وجود فروق معنوية بين الاختبار القبلي والبعدي ولصالح الاختبار

ويعزو السبب في ذلك الى تأثير المنهج التدريبي المقترح في انقاص الوزن لدى الأساتذة المشاركين في دورة تخفيض الوزن الزائد نتيجة بذل جهد بدني كبير خلال أيام التدريب الذي أدى الى احتراق السعرات الحرارية وبذلك استهلاك الكثير من الدهون المخزونة في الجسم مما أدى الى انخفاض ملحوظ في الوزن وحصول نطور في معدل النبض في وقت الراحة وفي السعة الحيوية ولذلك الاستهلاك القصوي للأوكسجين وهذا كله ناتج من تاثثر المنهج التدريبي المقترح الذي أدى الى تطور الجهاز التنفسي.

واوصت الدراسة بوضع برنامج غذائي مقترح مع الدورات الخاصة بتخفيض الوزن وتطبيقها على عينات 


\section{Abstract.}

\section{The effect of training curriculum proposal in weight loss and some functional variables on the professors in the faculty of Education University of Mustansiriya.}

The study aimed to identify the impact of the training cumiculum on some functional variables and the body weight of the masters course in weight reduction and to identify the proportion of the evolution on regardless functional variables on the body weight.

The study was conducted on a sample of professors in the facuity of education / university of mustansiriya and the number $\{25\}$ professors of the total $\{34\}$ professors of the participants in the course of the technique used in the selection of the sample algshawayah and allantgj shown in functional test.

There were no significant differences between pretest and posttest and favor of the posttest attribute the reason for this is the impact proposed training curriculum in weight loss among participants in the masters course to reduce over weight as a result exert great physical effort during days which led to the burning of calories and so a lot of stored fat can sumption in the body leading to a significant decrease in weight and get ttorvipulse rate at rest and in vital capacity as well as maximum oxcegen consumption and all of this resulted from the impact of the proposed training curriculum which led to the development of the respire tory system.

The study recommended and put Gmaga proposed program with special courses for weight loss and applying them to other samples.

$$
\begin{aligned}
& \text { 1- المبحث الأول: التعريف بالبحث. } \\
& \text { 1-1 } \\
& \text { إن التقدم الذي اجتاح مجتمعات العالم الجديد يتطلب بناء جسمي ووظيفي كامل لكل فرد من أفراد المجتمع } \\
& \text { لذا فالمستويات المتطورة والصحة الجيدة هي الهدف الأساسي للياقة البدنية والتدريب، وأن طاقة التدريبات الرياضية } \\
& \text { والمسابقات تعمل بشكل مؤثر على تحقيق ذلك. } \\
& \text { فالتدريب يحقق الصحة الوظيفية لأعضاء الجسم الداخلية نتيجة ممارسة التمرينات الرياضية حسب الأسس } \\
& \text { العلمية الصحيحة، فضلاً عن أن المحتوى الاساسي بتهيئة الجسم تكمن في تطوير القابلية الفسيولوجية والتي يعبر عنها } \\
& \text { الجسم في كفاءة صحة القلب والرئتين ومكونات الدم والجهاز العضلي والهضمي وغيرهما من الأجهزة الداخلية وهي التي } \\
& \text { تقدر درجة الصحة العامة والنشاط الذي يتمتع به الفرد. }
\end{aligned}
$$


وتكمن أهمية البحث هنا في إرساء أسس علمية لوضع متطلبات تدريبية مقترحة في إنقاص الوزن للأساتذة المشتركين في دورة تخفيض الوزن الزائد ورفع كفاءة الأجهزة الوظيفية لأساتذة الجامعة المستصرية الذين يعانون من زيادة في الوزن ومنحهم الثقة في حركتهم ونشاطهم وذلك من خلال إكسابهم وزن مثالي ولياقة عالية وصحة جيدة منمنلة في كفاءة الجهازين الدوري والتتفسي وغيرهما من الأجهزة الوظيفية. 2-1 2- 2 2 مشكلة البحث:

تعد الزيادة في الوزن من المشكلات الصحية التي يعاني الكثيرون منها والتي تسبب العديد من الأمراض منها أمراض القلب التاجية في ارتفاع ضغط الدم، أمراض السكري، وغيرها من الأمراض مثلاً هناك ارتفاع في معدلات السمنة وبشكل كبير بين شرائح المتمع المختلفة وخصوصاً في مجتمع الأساتذة حيث لوحظ في الآونة الأخيرة ازدياد نسبة البدانة في هذا المجتمع، إذ أن من أهم العوامل السلبية التي أدت إلى تفثي هذه الحالة هو التدني في مسنويات المجهود الحركي والنشاط البدني، لذا تكمن مشكلة البحث بوجود بعض الأساتذة الذين يعانون من الوزن الزائد وضعف في الجهازين الدوري والتتفسي وهذا ما يؤثر على نشاطهم اليومي وقابليتهم الحركية.

3-1

1. التعرف على تأثثر المنهج التدريبي على بعض المتغيرات الوظيفية وعلى وزن الجسم للأساتذة في دورة تخفيض الوزن. 2. التعرف على نسبة التطور الحاصل على بعض المتغيرات الوظيفية وعلى وزن الجسم للأساتذة المشاركين في دورة تخفيض الوزن. 4-1 1. هناك فروق ذات دلالة إحصائية بين الاختبار القبلي والاختبار البعدي على بعض المتغيرات الوظيفية وعلى وزن الجسم لدى الأساتذة المشاركين في دورة تخفيض الوزن. 2. هناك فروق ذات دلالة إحصائية في التطور الحاصل على بعض المتغيرات الوظيفية وعلى وزن الجسم للأساتذة المشاركين في دورة تخفيض الوزن.

\section{5-1}

1. المجال البشري: عينة من أساتذة كلية التربية / الجامعة المستصرية من الذين يتسمون بالسمنة وعددهم (25). 2. المجال الزماني: الفترة من السبت 2009/6/27 لغاية الاحد 2009/8/30. 3. المجال المكاني: قاعة اللياقة البدنية في الجامعة المستتصرية وملعب كرة القدم. 


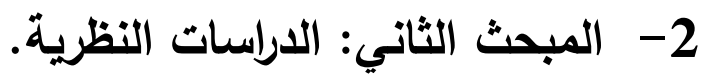 \\ 1-2}

تتثير الدراسات الصحية التي أجريت في العالم في السنوات الأخيرة إلى ارتفاع معدلات السمنة إلى مستويات كبيرة جعلت من الضروري الاهتمام بهذه المقلقة وغير الصحية، وساهمت عدة عوامل في انتشار هذه الظاهرة السلبية في الآونة الأخيرة من أهمها ارتفاع القوة الثرائية بين شرائح المجتمع وانتثار مطاعم الوجبات السريعة وتغيير العادات الغذائية مع تدني مستويات المجهود الحركي والنشاط البدني لذلك يمكن تعريف السمنة "هي زيادة حجم وعدد خلايا الثحم في جسم الإنسان يؤدي في الغالب إلى إضعاف صحة المعافي منها، حيث يقدر عدد خلايا الثحم في جسم الإنسان بحوالي 30-35 بليون خلية ويزداد حجم هذه الخلايا في البداية حينما يبدأ جسم الإنسان باكتتاز الثحم ثم يزداد

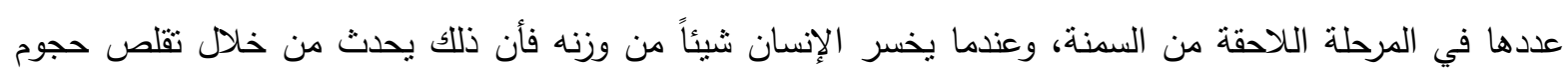
خلايا الثحم وليس في أعدادها.(20:5)

وهذا يفسر أسباب الصعوبة التي يواجهها الإنسان في التخلص من الثحم والبدانة حال كسبه بعض

$$
\text { الكيلوغرامات في وزنه. }
$$

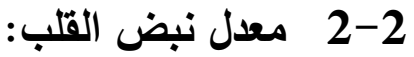

يعد معدل نبض القلب أي عدد ضربات القلب من المؤشرات المهمة التي يعتمد عليها عند إجراء الاختبارات

الخاصة بقياس نبض القلب، لهذا فان معدل نبض القلب هو "عبارة عن ضربات القلب في الدقيقة الواحدة.(77:8) لذلك فان معدل القلب "ينخف مع النمو منذ الميلاد حتى 20-25 سنة في وقت الراحة لدى الأفراد في نفس الجنس، إلا أن معدل القلب في الأعمار المختلفة له علاقة خطية مع الحد الأقصى لاستهلاك الاوكسجين كما أن معدل القلب لدى الأطفال وكبار السن عند أداء الحمل الأقل من الأقصى أعلى منه بالنسبة للثباب (20-35 سنة) كما يقل الحد الأقصى لمعدل القلب تدريجياً مع زيادة العمر مثلاً يبلغ الحد الأقصى لمعدل القلب لدى الذكور والإناث في عر 10 سنوات 210 ضربة/دقيقة وفي عمر 25 سنة ذكور وإناث 195 ضربة/دقيقة وفي عمر 50 سنة 175 ضربة/دقيقة وفي عمر 65 سنة 165 ضربة/دقيقة.(227:10)

\section{3-2}

نعني بالسعة الحيوية "هي سحب أكبر كمية من الهواء في عملية الثهيق وأوطئ كمية في الهواء في عملية الزفير، أي أكبر حجم من الهواء نسنطيع الرئتين تبادله وقد يصل إلى 3-5 لتر في كل مرة، هذا بالنسبة لغير الرياضي، أما بالنسبة إلى كمية الأوكسجين الذي تكون نسبته المئوية في الهواء المستشق 21\% في عملية الزفير تتخفض إلى 16\% من هذا نسنطيع القول بأن عملية الامتصاص في الدم تتم بمقدار 500 ملليتر في كل مرة في التتفس، وحوالي 25 ملليتر من الأوكسجين ويحل محله كمية منساوية من ثاني أوكسبد الكاربون.(109:7) 


\section{2-4 الاستهلاك القصوي للأوكسجين النسبي:}

يعبر عن هذا الحد الاقصى النسبي لاستهلاك الأوكسجين بعدد ملليترات الاوكسجين مقابل كل كيلوغرام من وزن الجسم في الدقيقة الواحدة، وتحسب بنسبة الحد المطلق الأفصى الاستهلاك الاوكسجين بالملليترات على وزن الجسم بالكيلوغرام فيكون الناتج ؟؟؟؟؟ ملليتر / كغم / دقيقة وحتى مرحلة البلوغ (13-14 سنة) لا نوجد فروق بين البنين والبنات في مقدار الحد الأقصى المطلق، ولكن بعد هذه المرحلة فأن الحد الأقصى المطلق لدى الإناث يقل دائماً عن الذكور بمقدار 25-30\% ويصل الإنسان إلى أقصى متوسط للحد الأقصى لاستهلاك الاوكسجين المطلق في سنة 1820 سنة ثم يقل بعد ذلك تدريجياً مع زيادة العمر حتى يصل في عمر 60-70 سنة إلى حوالي 70\% من مسنوى الحد الأقصى لاستهلاك الاوكسجين في عمر 20-30 سنة، ويرجع اختلاف الحد الأقصى لاستهلاك الاوكسجين بين الأطفال والكبار والذكور والإناث إلى اختلاف وزن الجسم ويقل الفرق بين الذكور والإناث في مقدار الحد الاقصى النسبي لاستهلاك الاوكسجين حيث تقل الإناث عن الذكور بمقدار 15-20\% مقابل 25-30\% بالنسبة للاستهلاك المطلق.(303:10)

\section{3- المبحث الثالث: منهجية البحث وإجراء|ته الميدانية. 1-3 منهج البحث:}

استخدم الباحثون المنهج التجريبي كونه يتلاعم مع مشكلة البحث.

\section{2-3 2-3 عينة البحث:}

تألفت عينة البحث من أساتذة كلية التربية / الجامعة المستتصرية والبالغ عددهم (25) أستاذ من مجموع (43) أستاذ من مجتمع البحث الأصلي المشتركين في دورة تخفيض الوزن الزائد، واستخدم الباحثون الطريقة العشوائية في اختيار عينة البحث من الذين تتراوح أعمارهم من (35-40) سنة حيث كانت نسبة العينة (58,1\%).

\section{3-3 تجانس عينة البحث:}

للتعرف على مواصفات العينة من حيث حسن اختيارها ومدى نوزيعها نوزيعاً طبيعياً ومتجانساً في ما بين أفراد العينة، تم حساب معامل الالتواء لقياس الوزن والطول والعمر لبيان تجانسهم، إذ كانت النتائج ضمن الحدود

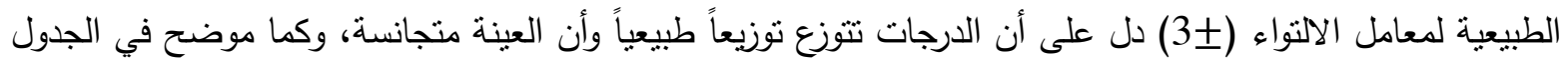

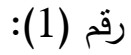


مجلة كلية التربية الرياضية - جامعة بغداد * المجلد الثامن والعشرون ** العدد الأول * لسنة

الجدول (1)

يوضح معامل الالتواء لعينة البحث لمتغيرات العمر - الطول - الوزن

\begin{tabular}{|c|c|c|c|c|}
\hline معامل الالتواء & الانحراف المعياري & الوسيط & الوسط الحسابي & المتغيرات \\
\hline $1,48^{-}$ & 6,12 & 37 & 33,98 & العمر \\
\hline 1,25 & 7,46 & 175 & 178,11 & الطول \\
\hline 1,5 & 14,13 & 96 & 103,17 & الوزن \\
\hline
\end{tabular}

-3-3 و وسائل وأدوات البحث المستخدمة:

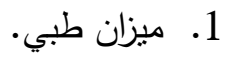

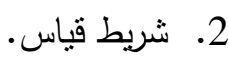

3.

4. - 5 ساعة نوقيت عدد (2).

5. كرات طبية وكرات قدم وكرات طائرة.

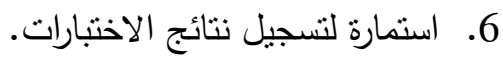

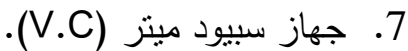

5-3 الاختبارات الوظيفية المستخدمة:

3-5-3 1 اختبارات قياس معدل النبض وقت الراحة.(46:2

• • • هدف الاختبار: قباس معدل نبض القلب وقت الراحة.

• وصف الاختبار: يقوم المختبر بالاستلقاء بشكل طولي وبعد راحة نامة مدة (10) دقائق يتم قياس النبض عن

طريق وضع السبابة على الثريان السباني المار أعلى الرقبة وتحت الذقن أو عن طريق الثريان في رسن اليد.

التسجيل: يتم الحصول على معدل ضربات القلب خلال (30) ثانية، ثم الضرب (22) يتم الحصول على معدل

ضربات القلب خلال دقيقة واحدة.

2-5-3 2-5 اختبار السعة الحيوية:

• • ماف الاختبار: قياس السعة الحيوية المطلقة. (273:3)

• وصف الأداء: يمسك المختبر أنبوب النفخ المطاطي المربوط بجهاز السبيروميتر في وضع الوقوف، ثم يبدأ بأخذ أقصى شهيق ممكن، بعد ذلك يقوم برفع أقصى زفير ممكن في الأنبوب المطاطي بعد ذلك يقوم الجهاز بالقياس ذاتياً مع مراعاة وضع سداة على أنف الدختبر لضمان عدم خروج الهواء من الأنف. 
مجلة كلية التربية الرياضية - جامعة بغداد * المجلد الثامن والعشرون * العدد الأول ** لسنة

• التسجيل: يقوم فريق العمل* بتدوين النتائج التي حصلوا عليها من الجهاز والتي تمتل حجم الهواء المدفوع في

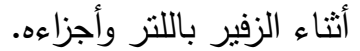

3-3-3 3 اختبار الركض 1,5 ميل.(22:14)

• هدف الاختبار: قياس القدرة الاوكسجين والاستهلاك القصوي للأوكسجين النسبي (R- Vo,max). • وصف الاختبار: يقوم المختبر بالركض بصورة مستمرة على مسافة (1,5 ميل) والتي تعادل (2414م)، يقوم المساعد بالتوقيت عند بدء المختبر بالركض عند بداية المسافة ويتم إيقاف الساعة عند نهاية المسافة، يتم الاختبار بصورة جماعية مرة واحدة.

• التسجيل: ويتم حساب الزمن بالدقائق وأجزائها، وتتم موازنة الوقت وفق جدول معدل لهذا الغرض، الذي يبين

مقدار الاستهلاك القصوي بالأوكسجين النسبي (R- Vo 2 max)، كما مبين في الجدول رقم (2)

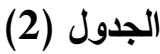

يبين نسبة (R- Vo,max) عن طريق الزمن المنجز عند قطع مسافة 1,5 ميل

\begin{tabular}{|c|c|c|c|c|c|}
\hline $\begin{array}{c}\text { (R- Vo2max) } \\
\text { مل/كفم /دقيقة }\end{array}$ & 1,5 ميل / دقيقة & $\begin{array}{c}\text { (R- Vo2max) } \\
\text { مل/كفم /دقيقة }\end{array}$ & 1,5 ميل / دقيقة & $\begin{array}{c}\text { (R- Vo2max) } \\
\text { مل/كغم /دقيقة }\end{array}$ & 1,5 ميل / دقيقة \\
\hline 31 & $15,30-15,01$ & 46 & $11,30-11,01$ & 75 & 7,30 \\
\hline 30 & $16-15,30$ & 44 & $12-11,30$ & 72 & $8-7,31$ \\
\hline 28 & $16,30-16,01$ & 41 & $12,30-12,01$ & 67 & $8,30-8,01$ \\
\hline 27 & $17-16,31$ & 39 & $13-12,31$ & 62 & $9-8,31$ \\
\hline 26 & $17,30-17,01$ & 37 & $13,30-13,01$ & 58 & $9,30-9,01$ \\
\hline 25 & $18-17,31$ & 36 & $14-13,31$ & 55 & $10-9,31$ \\
\hline & & 34 & $14,30-14,01$ & 52 & $10,30-10,01$ \\
\hline & & 33 & $15-14,31$ & 49 & $11-10,31$ \\
\hline
\end{tabular}

6-3

2-6-3-3 1-3 الاختبارات القبلية:

أجرى الباحثون الاختبارات القبلية لأفراد عينة البحث في كفاءة اللياقة الرياضية في الجامعة المستتصرية يوم

السبت 2009/6/27 الساعة 8,30 صباحاً، حيث نم إجراء الاختبارات الوظيفية وانتهت في اليوم نفسه. 


\section{مجلة كلية التربية الرياضية - جامعة بغداد * المجلد الثامن والعشرون ** العدد الأول ** لسنة}

3-6-2-3 تنفيذ البرنامج التدريبي المقترح:

قام الباحثون بتتفيذ المنهج التدريبي المقترح لمدة 60 يوماً من 2009/6/27 ولغاية 2009/8/30 على طول أيام الأسبوع عدا أيام الجمعة وأيام العطل الرسمية، ولمدة (1:30) ساعة ونصف يومياً، وتبدأ الساعة التدريبية الأولى الساعة 8,30 صباحاً وقد راعا الباحثون الثدد وفترات الراحة بما تتتاسب وقدرات افراد العينة.

\section{3-6-3 الاختبارات البعدية:}

أجرى الباحثون الاختبارات البعدية بعد الانتهاء من المنهج التدريبي المقترح وذلك يوم 2009/8/16

المصادف يوم الأحد في الساعة الثامنة والنصف صباحاً، وحرصاً على إجراء الاختبارات البعدية تحت نفس ظروف الاختبارات القبلية.

\section{3-3 الوسائل الإحصائية:}

استخدم الباحثون البرنامج (SPSS) من الحقيبة الإحصائية، ونم آلياً حساب كل ما يأتي:

$$
\begin{aligned}
& \text { 1. الوسط الحسابي.(56:12) = مَسس ن } \\
& =(274: 15) \cdot \mathrm{T} \text {-test } .2
\end{aligned}
$$

$$
\frac{2 \omega-1 \omega}{\sqrt{\frac{2 \varepsilon+1 \varepsilon}{1-\dot{v}}}}=
$$

3. الاتحراف المعياري. (156:13)

4. معامل الالتواء. (112:11) 5. 
مجلة كلية التربية الرياضية ـ جامعة بغداد * المجلا الثامن والعشرون ** العدد الأول ** لسنة

4- المبحث الرابع: عرض النتائج وتحليلها ومناقشتها.

الجدول (3)

يبين متوسط الفروق والخطأ المعياري لها ودلالة الفروق بين الاختبارين القبلي والبعدي لعينة البحث في اختبار الوزن والمتغيرات الوظيفية

\begin{tabular}{|c|c|c|c|c|c|}
\hline دلالة الفروق & ت الجدولية & ت المحتسبة & ف هـ & ف & المتغيرات \\
\hline معنوي & 1,71 & 2,39 & 4,03 & 9,67 & 1- وزن الجسم \\
\hline معنوي & 1,71 & 2,15 & 2,28 & 4,91 & 2- نبض القلب \\
\hline معنوي & 1,71 & 4,62 & 0,08 & 0,37 & 3- السعة الحيوية \\
\hline معنوي & 1,71 & 2,37 & 2,87 & 6,83 & $\mathrm{R}-\mathrm{vo}_{2} \mathrm{Max}-4$ \\
\hline
\end{tabular}

يبين الجدول رقم (3) نتائج اختبار الوزن والاختبارات الوظيفية بين الاختبارين القبلي والبعدي لعينة البحث، حيث أظهرت النتائج لاختبار الوزن المتوسط الفروق (9,67) والخطأ المعياري (4,03) حيث بلغت قيمة (ت) المحتسبة (2,39) وهي أكبر من قيمة (ت) الجدولية والبالغة (1,71) عند مستوى خطأ (0,05) ودرجة حرية (24)، وهذا يبين وجود فروق معنوية بين الاختبارين القبلي والبعدي ولصالح الاختبار البعدي.

أما اختبار نبض القلب عند وقت الراحة، فقد أظهرت النتائج أن متوسط الفروف (4,91) والخطأ المعياري (2,28)، فقد بلغت قيمة (ت) المحتسبة (2,15) وهي أكبر من قيمة (ت) الجدولية والبالغة (1,71) عند مسنوى خطأ (0,05) ودرجة حرية (24) وهذا يبين وجود فروق معنوية بين الاختبارين القبلي والبعدي ولصالح الاختبار البعدي. وأما اختبار السعة الحيوية، فقد اظهرت النتائج أن منوسط الفروق (0,37) والخطأ المعياري (0,08)، فقد بلغت قيمة (ت) المحتسبة (4,62) وهي أكبر من قيمة (ت) الجدولية والبالغة (1,71) عند مسنوى خطأ (0,05) ودرجة حرية (24) وهذا يبين وجود فروق معنوية بين الاختبارين القبلي والبعدي ولصالح الاختبار البعدي. أما اختبار الاستهلاك القصوى للأوكسجين النسبي R-vo2 Max فقد أظهرت النتائج أن منوسط الفروق (6,83) والخطأ المعباري (2,88)، فقد بلغت نسبة (ت) المحتسبة (2,37) وهي أكبر من قيمة (ت) الجدولية والبالغة (1,71)، عند مستوى خطأ (0,05) ودرجة حرية (24) وهذا بيين وجود فروق معينة بين الاختبارين القبلي والبعدي ولصالح الاختبار البعدي.

تشير نتائج اختبار الوزن والاختبارات الوظيفية وجود فروق معنوية بين الاختبار القبلي والبعدي ولصالح الاختبار البعدي ويعزو السبب في ذلك إلى تأثير المنهج التدريبي المقترح في انخفاض الوزن لاى الأساتذة المشاركين في 
دورة تخفيض الوزن الزائد وذلك "بيذل جهد بدني كبير أيام التدريب الذي أدى إلى احتراق الكثير من السعرات الحرارية وبالتالي استهلاك الكثير من الدهون المخزونة في الجسم مما أدى إلى انخفاض ملحوظ في الوزن.(98:16)

لقد ذكر عباس علي عذاب: "إن التدريب المنتظم يؤدي إلى نقص ذي دلالة معنوية في معدل نبض القلب في أثناء الراحة ولممارسة التدريب بشكل منتظم ينتج عنه زيادة في قدرة العضلة القلبية على الانقباض والانبساط مما يؤدي إلى زيادة حجم الدفع القلبي وينتج عنه زيادة في فعل العصب الباراسمبثاوي الذي يعمل على إبطاء معدل ضربات القلب.(86:4)

أما نتائج اختبار السعة الحيوية فتعزو الباحثة ذلك إلى مساهمة المنهج التدريبي المقترح في تطوير كفاية الجهاز التتفي، وذللك من خلال تحسين قدرة الرئتين إلى استيعاب كمية أكبر من الهواء عند الثهيق أو نتيجة الزيادة في كمية الهواء المدفوعة على حساب كمية الهواء المنتقية في الرئتين.

لقد ذكر ماهر عبد اللطيف: "إن مزاولة التدريب الرياضي بصورة منتظمة نؤدي إلى حدوث تغييرات وظيفية إيجابية في الجهاز التتفسي، هذه التغيرات تحقق مرونة إضافية في عضلات القفص الصدري مما يزيد من قابليتها على التمدد والاتساع الذي يؤدي إلى ازدياد حجم الهواء المستتشق ومن ثم يساعد على زيادة كمية الاوكسجين في عملية تبادل الغازات بين الدم والحويصلات الهوائية والاقتصاد في حركات ثم التتفس بسبب زيادة السعة الحيوية.(72:9) كما أن "الانتظام في التدريب يعمل على زيادة قابلية الثخص على دفع الهواء بقوة إلى الرئنين وكذلك حدوث زيادة في الحجم الكلي للهواء الذي يمكن استنشاقه أكثر من غير المتدربين.(143:17) أما بالنسبة لاستهلاك الاوكسجين القصوي النسبي فقد اثار (Giorgetti) بالتدريب، وهذه الزيادة تحصل كرد فعل للعضلات القائمة بالجهد وتعودها على استخلاص كمية أكبر من الاوكسجين الذي يؤهل العضلة مع زيادة كفايتها وتقليل الحامضية الناتجة عن التمثيل الغذائي الحد الأدنى. (90:18)

جدول (4)

يبين قيم الأوساط الحسابية للاختبارين القبلي والبعدي لعينة البحث ونسبة التطور في اختبار الوزن والمتغيرات

الوظيفية

\begin{tabular}{|c|c|c|c|}
\hline نسبة التظور & سَ بعدي & سَ قبلي & المتغيرات \\
\hline$\% 13,06$ & 89,69 & 103,17 & 1- وزن الجسم \\
\hline$\% 5,78$ & 86,17 & 91,46 & 2- نبض القلب \\
\hline$\% 19,5$ & 2,88 & 2,41 & 3- السعة الحيوية \\
\hline$\% 19,98$ & 30,74 & 25,62 & $\mathrm{R}-\mathrm{vo}_{2}$ Max -4 \\
\hline
\end{tabular}


الجدول (4) يبين قيم الأوساط الحسابية للاختبارين القبلي والبعدي ونسبة التطور لاختبار الوزن والمتغيرات الوظيفية، حيث أظهرت النتائج لاختبار الوزن للوسط الحسابي للاختبار القبلي (103,17) والوسط الحسابي للاختبار البعدي (88,69)، وبعد استخدام قانون نسبة النطور بلغت نسبة النطور (13,06\%).

أما اختبار معدل نبض القب أثناء الراحة، فقد أظهرث النتائج أن الوسط الحسابي القبلي $(91,46)$ والوسط الحسابي للاختبار البعدي (86,17)، أما نسبة النطور فقد بلغت (5,78\%).

أما بالنسبة لاختبار السعة الحيوية، فقد أظهرت النتائج بأن الوسط الحسابي للاختبار القبلي (2,41)، والوسط الحسابي للاختبار البعدي (2,88)، أما نسبة النطور فقد بلغت (19,51\%).

أما اختبار الاستهلاك العضوي للأوكسجين فقد أظهرت النتائج بأن الوسط الحسابي للاختبار القبلي بلغ (25,62) والوسط الحسابي للاختبار البعدي (30,74)، أما نسبة النطور فقد بلغت (19,98\%).

يعزو الباحثون التطور الحاصل في انخفاض وزن الجسم لدى الأساتذة المشاركين في دورة تخفيض الوزن الزائد، إلى "إن التمرينات تعمل على تخليص جس الإنسان من مقدار معين من السعرات الحرارية التي ينتاولها في غذائه، فيقل وزن الجسم عندما تزداد كمية السعرات الحرارية المفقودة نتيجة للتدريب والتمرينات عن السعرات الحرارية التي يتتاولها اللاعب.(17:1)

إن النقص في السعرات المأخوذة عن الاحتياجات سوف يدفع الجسم لتمثيل المواد المخزونة بالجسم لإمداده بالطاقة ونشاطه الحيوي في البداية يتم استهلاك الأوكسجين المخزون من الكليوكوجين ثم بعض البروتينات القليلة في الدم ثم المخزون الدهني ويستمر هذا الحال من استهلاك الدهون إلى أن بصل الوزن المرغوب فيه.

أما النطور الحاصل في معدل نبض القلب وقت الراحة فيعزو الباحثون إلى المساهمة الفاعلة من قبل المنهج التدريبي المقترح في العمل الوظيفي للقلب، إذ أن التدريب يؤدي دوراً مهماً في نظوير الحالة الوظيفية للقلب من الناحية الفسيولوجية، فمن اهم نتائج عملية النطوير هو انخفاض معدل ضربات القلب وذلك لزيادة حجم الضربة ومن ثم زيادة الناتج القلبي في كل ضربة من ضربات القلب. "إن التدريب المنتظم يعمل على تكيف القلب للمجهود الذي يؤدي إلى انخفاض معدل ضربات القلب أثثاء الراحة، عند إعطاء أعمال تدريبية مختلفة مقابله بأشخاص غير متدربين بشكل منتظم وذلك بسبب كمية الدم المدفوعة في الضربة الواحدة وزيادة فترة الراحة بين الضربة القلبية والتي تليها.(125:19) أما بالنسبة للنطورات الحاصلة في السعة الحيوية فيعزو الباحثون إلى أن التدريب الرياضي يؤدي إلى ازدياد السعة الحيوية نتيجة لازدياد قابلية العضلات الصدرية على التمرن. (12:11) 
أما النطور الحاصل في الاستهلاك القصوي للأوكسجين فيعزو الباحثون إلى أن تأثنير المنهج التدريبي المقترح الذي أدى إلى تطور الجهاز التتفسي وهو الجزء الرئيس في إمداد الجسم بالأوكسجين وتكوين الطاقة اللازمة للجهد العضلي.

\section{5- المبحث الخامس: الاستتناجات والتوصيات.

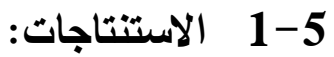

1. التوصل إلى وضع منهج تدريبي يعمل على انقاص الوزن وتطوير الصفات الفسيولوجية. 2. انقاص وزن الأساتذة المشاركين في دورة تخفيض الوزن وتطوير بعض المتغيرات الفسيولوجية لديهم. 2-5 1. عل بحوث مشابهة أخرى على المتغيرات فسيولوجية أخرى. 2. عل بحوث مشابه تطبق على اللاعبين. 3. وضع برنامج غذائي مقترح مع الدورات الخاصة بتخفيض الوزن.

المصادر.

1. أثرف حافظ حمود: أثز انخفاض الوزن المتعدد على بعض المتغيرات النفسية لدى اللاعبين، أطروحة دكتوراه، جامعة حلوان، كلية التربية الرياضية للبنين في القاهرة. 2. امر الهه السباطي: أسس وقواعد التدريب الرياضي وتطبيقاته، الإسكندرية، مطبع الانتصار، 1998. 3. هاثم عدنان الكيلاني: الأسس الفسيولوجية للتدريبات الرياضية، ط1، الكويت، مكتبة الفلاح، 2000. 4. عباس علي عذاب: تأثير تدريب الضفادع البشرية في بعض الخصائص الفسيولوجية، رسالة ماجستير ، كلية التربية

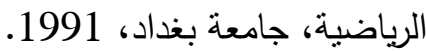
5. عادل علي حسين، جامعة النهرين، المعارف - الإسكندرية، 1995.

6. مصطفى حسين باهر : المعادلات العلمية بين النظرية والتطبيق، القاهرة، مركز الكتاب للنشر، 1999. 7. فاضل سلطان الخالدي: وظائف الأعضاء والتدريب البدني، ج1، الاتحاد العربي السعودي للطب الرياضي، .1990

8. محمد صبحي أبو صالح: الطرق الإحصائية، ط1، عمان، دار الليازوري العلمية للنشر والتوزيع، 2000. 9. قاسم حسن حسين: الفسيولوجيا مبادئها وتطبيقاتها في المجال الرياضي، بيروت، مطبعة دار الحكمة للطباعة والنشر، 


\section{مجلة كلية التربية الرياضية - جامعة بغداد ** المجلد الثامن والعشرون ** العدد الأول * لسنة}

10. ماهر عبد اللطيف عارف: أثز برنامج مقترح في تطوير بعض المتغيرات الفسيولوجية، رسالة ماجستير ،لية التربية الرياضية، جامعة بغداد، 1991.

11. محمد حسن علاوي، ابو العلا أحمد عبد الفتاح: فسيولوجيا التدريب الرياضي، دار الفكر العربي، 2000.

12. محمد صبحي حسنين: القياس والتقويم في التربية الرياضية، ج1، ط3، القاهرة: دار الفكر للنشر، 1999.

13. موراى شيجل: ملخصات شوم / نظريات وسائل الإحصاء، نرجمة شعبان عبد الحمبد شعبان، ط5، القاهرة: الدار

$$
\text { الدولية للنشر والتوزيع، } 1998 .
$$

14. وديع ياسين، وحسن محمد عبد العبيدي: التطبيقات الإحصائية واستخدام الحاسوب في بحوث التربية الرياضية،

$$
\text { الموصل: دار الكتب للطباعة والنشر. }
$$

15. Gen M. Adams. Exercise Physiology Laboratory Manul, v-s-A, WM- G Brown publishers.

16. Exkerts, Hellen, practical measurement physical performance, phiddelea and Febiger, 1984.

17. Yaughan thomos. Exerdise phyologe. Ed, Granda publishing Limited, G-B- 1975.

18. Bruce J. Noble. Physology of Exercise and sport times mirror, Mosby collge pubis jers, U.S.A, 1986.

19. C. Grorgetti and Others, sport cardiology, Rdation ship betreen gaggi publisher, printed in Italy, 1980.

20. Harbert A. Devries, Physiology of Exercise, $3^{\text {rd }}$ Ed-W-M-C- Brown company Printed in U.S.A, 1980. 